\title{
MARKETING VERDE: PROPOSTA DE ATITUDES SUSTENTÁVEIS EM BIBLIOTECAS
}

\section{GREEN MARKETING: PROPOSAL FOR SUSTAINABLE LIBRARY ATTITUDES}

Genilson Geraldoa

Marli Dias de Souza Pinto ${ }^{b}$

\begin{abstract}
RESUMO
Introdução: O Marketing Verde é uma ferramenta relevante deve fazer parte do planejamento estratégico de grandes, médias e pequenas organizações, bem como de órgãos governamentais e não governamentais. Apresentando-se como um mecanismo importante para fixar imagem positiva e demonstrar a preocupação das organizações com e sem fins lucrativos com a qualidade de vida do planeta e da sociedade em geral. Este estudo aponta a perspectiva que o Marketing Verde tem e pode ser adequado para as Bibliotecas, como responsáveis que são, pelo acesso, uso e disseminação da informação a sua comunidade usuária, reforçando ações de desenvolvimento sustentável no contexto atual e para as gerações futuras. Objetivo: Deste modo o objetivo deste artigo é propor a implementação de Marketing Verde em Bibliotecas. Justifica-se ainda, que esta temática precisa de ampla reflexão e inserção, uma vez que a sustentabilidade é um dos conceitos mais discutidos e idealizados atualmente. Metodologia: Caracteriza-se como uma pesquisa aplicada e exploratória como procedimentos técnicos a pesquisa bibliográfica e documental, com proposição de implementação de Marketing Verde para as Bibliotecas a partir do modelo adaptado da proposta de Eckschmidt e Beskow (2014). Resultados: apresenta-se propostas para conhecer os princípios, conceitos e alcançar os objetivos do desenvolvimento sustentável, e a relevância do uso do Marketing Verde em Bibliotecas, demonstrando procedimentos que podem ser implementados em ações sustentáveis para realização do Marketing Verde, que vão ao encontro com a Agenda 2030 e os Objetivos de Desenvolvimento Sustentável da ONU.
\end{abstract}

Descritores: Green Marketing. Greenwashing. Marketing Verde. Bibliotecas. Informação Sustentável.

\footnotetext{
a Bacharel em Biblioteconomia pela Universidade Federal de Santa Catarina (UFSC). genilsongeraldo.biblio@gmail.com

b Doutora em Engenharia de Produção pela Universidade Federal de Santa Catarina (UFSC). Professora do Programa de Pós-Graduação em Ciência da Informação da Universidade Federal de Santa Catarina (UFSC).marli.dias@ufsc.br
} 


\section{INTRODUÇÃO}

O mundo está passando por um processo de mudança, em que a harmonia entre o ser humano e meio ambiente está na pauta de discussão nacional e mundial. Órgãos governamentais e não governamentais, organizações e consumidores não admitem mais comprar e usufruir de produtos que agridem o meio ambiente, e consequentemente, a espécie humana.

Este fato tem repercussão e pode muitas vezes ser consequência do arraigado hábito de consumo exagerado da sociedade e, atualmente, impõemse uma mudança comportamental importante, em prol da causa ambiental. Neste contexto, surge um novo conceito de Marketing denominado Marketing Verde ou Green Marketing. Para Kotler (2002), Marketing Verde é o estudo dos aspectos positivos e negativos das atividades de marketing em relação ao uso dos recursos não renováveis. Com isso, organizações, diferentes entidades e profissionais de marketing vem buscando realizar campanhas e atitudes "ecologicamente corretas", com objetivo de promover uma imagem positiva dentro dos padrões do desenvolvimento sustentável.

Entretanto, ao planejar o marketing verde, tem que se ter cuidado redobrado, principalmente por ser tratar de um assunto complexo e, com mais exigências populares e de organizações não governamentais especializadas, podendo vender "gato por lebre" (ECKSCHMIDT; BESKOW, 2014). O termo utilizado nesta situação é denominado de Greenwashing, no qual simboliza ações "ditas" de marketing verde. Entidades que realizam ações sustentáveis, não exatamente atitudes ecológicas.

Eckschimidt e Beskow (2014) apontam que realizar ações que buscam a sustentabilidade, geralmente estão relacionadas a ideia de produto, entretanto, os autores expõem que a sociedade confunde sustentabilidade com "salvar a natureza". Ou seja, ações sustentáveis objetivam uma amplitude maior de atitudes, conscientização e planejamento. Sachs (2015) acredita que o desenvolvimento sustentável é um conceito central em que a sociedade vivencia contemporaneamente, ou seja, um caminho de entender o mundo e um método para resolver problemas globais. 
Em 2015, as Nações Unidas juntamente com chefes e representantes de vários estados se reuniram em Nova York (EUA), desenvolveram e apresentaram a Agenda 2030 e seus Objetivos de Desenvolvimento Sustentável (ODS). Adotaram uma decisão histórica sobre um "conjunto de objetivos e metas universais e transformadoras que é abrangente, de longo alcance e centrado nas pessoas". A ONU informa que estão comprometidos "a trabalhar incansavelmente para a plena implementação desta Agenda em 2030". (ONUBR, 2015, p. 3). A Agenda 2030 possui 17 objetivos de desenvolvimento sustentável, oferecendo um guia com 169 metas para que os países, empresas, organizações e cidadãos de todo mundo, possam alcançar até o ano de 2030.

A International Federation of Library Associations (IFLA) assumiu os ODS ao delegar as bibliotecas de todo mundo a perseguição por meio de ações e atividades dentro do seu escopo de apoiar, trabalhar e divulgar, os Objetivos de Sustentabilidade das Nações Unidas e, nacionalmente este compromisso foi assumido pela Federação Brasileira de Associação de Bibliotecários, Ciência da Informação e Instituições (FEBAB) tendo como lócus as bibliotecas brasileiras.

Nesta perspectiva, o Marketing Verde encaixa-se visivelmente nos objetivos da IFLA e FEBAB uma vez que envolve todos os atores neste processo e, como organizações que não visam lucro, as bibliotecas tem que fazer sua parte e apoiar e incentivar as metas sugeridas pela IFLA. Deste modo, é um trabalho contínuo que se faz necessário planejamento, análise e supervisão contínua do cumprimento desta proposta.

Neste contexto e levando-se em conta que a temática da sustentabilidade é um dos conceitos mais discutidos nos dias atuais, torna-se relevante o estudo focal desta pesquisa cujo objetivo visa: propor a implementação de Marketing Verde em Bibliotecas.

Como justificativa da temática, a mesma tem a perspectiva de contribuir para uma efetiva ação de planejamento de marketing em organizações informacionais e, como resultados, alinhando-se a futuras pesquisa na área da Ciência da Informação.

Metodologicamente a pesquisa caracteriza-se como uma pesquisa aplicada, com abordagem qualitativa, que utilizou de procedimentos técnicos da 
pesquisa bibliográfica e documental.

\section{ASPECTOS TEÓRICOS CONCEITUAIS}

Na seção 2, busca fundamentar o estudo, explanando a respeito de: Marketing Verde; Marketing Verde e Greenwashing; Objetivos de Desenvolvimento Sustentável; e Unidades de informação sustentáveis.

\subsection{MARKeting Verde}

O Marketing Verde é um novo conceito no mercado moderno, desenvolvendo uma importante ferramenta para o comércio atualmente. Segundo Mishra e Sharma (2014), o Marketing Verde é inevitável, sendo um interesse crescente entre os consumidores em todo mundo, exigindo produtos que possuam uma relação à proteção do meio ambiente.

Atualmente, evidencia-se uma crescente preocupação das pessoas com o meio ambiente e, com isso, uma importante mudança de comportamento. Como resultado disso, surgiu o marketing verde, que fala pelo mercado crescente de produtos e serviços sustentáveis e socialmente responsáveis. Ou seja, este momento é uma era dos produtos recicláveis, não tóxicos e amigos do ambiente. Isso se tornou o novo mantra para os profissionais de marketing que satisfazem as necessidades dos consumidores e obtêm melhores lucros. (MISHRA; SHARMA, 2014).

Com isso, percebe-se que a sociedade está passando por uma fase de mudanças de hábitos e comportamentos e, esta percepção, irreversivelmente, tem ampliado a visão de desenvolvimento, para uma visão consciente de desenvolvimento sustentável.

O marketing verde é visto como uma ferramenta mais abrangente do que apenas uma postura ecológica dos anos anteriores. Atualmente os consumidores, fornecedores e organizações em geral estão mais céticos e conscientes com relação às várias tentativas das organizações de passar uma imagem verde sem a real preocupação com o meio ambiente. (CASTRO et al., 2016). 
Mishra e Sharma (2014) apontam que o Marketing Verde é o processo de desenvolvimento de produtos e serviços, buscando satisfazer os clientes que preferem produtos de boa qualidade, bom desempenho e conveniência a um custo acessível, e ao mesmo tempo sem impacto negativo ao meio ambiente.

Os autores supracitados salientam ainda, que isto inclui dentro de uma ampla gama de atividades, como modificação do produto, "alteração do processo de produção, propaganda modificada, mudança de embalagem, etc.", objetivando reduzir o impacto negativo dos produtos e seu consumo e descarte no meio ambiente. (MISHRA; SHARMA, 2014, p.79, tradução nossa).

No meio organizacional, Moreira (2015) comenta que as questões ambientais estão cada vez mais presentes no planejamento estratégico, a fim de contornar pressões políticas, legais e sociais. E que desta forma, acredita que 0 Marketing Verde promove a ideia de que seja possível fomentar 0 desenvolvimento econômico organizacional com a diminuição de impactos ambientais.

\subsection{Marketing Verde ou Greenwashing?}

Visando entender até que ponto a discussão sobre o desenvolvimento sustentável tem sido utilizado e fomentar a percepção realmente sustentável, se faz necessária uma breve distinção entre os termos Marketing Verde e Greenwashing.

Tavares e Ferreira (2012) discorrem que esta discussão, torna-se relevante ao expor que este olhar deve estar atento quanto à diferenciação entre o que é propaganda, como foco sustentável, correspondendo a uma real prática, e o que é um "Greenwashing ou maquiagem verde", cuja mensagem é exclusivamente com finalidade lucrativa.

Greenwashing, segundo o Ecycle (2019), é um termo inglês que pode ser traduzido para o português como lavagem verde ou pintando de verde. Podendo ser praticado por organizações públicas, privadas e não governamentais (ONGs), governos ou políticos e indústrias. Na estratégia de promover discursos, anúncios, ações, documentos, propagandas e campanhas publicitárias sobre ser ambientalmente/ecologicamente correto, entretanto não correspondem a 
atitudes realmente sustentáveis.

Ottman (2012) expõe que o Greenwashing acontece, quando uma organização exagera ou engana os consumidores a respeito dos atributos ambientais de suas ofertas. Podendo surgir de diversas fontes, incluindo ambientalistas, imprensa, consumidores, concorrentes e comunidade científica, e podem ser sérias, duradouras e muito prejudiciais à reputação de uma empresa.

Para Ottman (2012) muitos consumidores podem se sentir confusos quando expostos a propagandas de produtos verdes, pois têm dificuldades em separar aqueles que realmente internalizam a variável "sustentável" em sua produção, comercialização e descarte, daqueles que apenas utilizam o termo como mais um artifício de marketing.

Diante disto, torna-se relevante que as organizações privadas, públicas e não governamentais, tenham uma equipe qualificada com conhecimento teórico e técnico, para promover campanhas de Marketing Verde, dando apoio necessário para que a comunicação e ações que sejam verdadeiramente exatas, honestas e transparentes. (ECKSCHMIDT; BESKOW, 2014).

Eckschmidt e Beskow (2014) acreditam que os consumidores atualmente, já possuem uma consciência sustentável e, podem desacreditar no modismo das sustentabilidades em um tipo de comprovação e crédito. Com isso, organizações públicas e privadas, organizações não governamentais e governos devem estabelecer um planejamento de metas e ações, buscando apresentar diretrizes que contemplam os ODS, beneficiando não apenas a imagem realmente sustentável e consciente da organização, mas inclusive ao meio ambiente, a humanidade e as gerações futuras, como é o caso dos ODS da Agenda 2030 da ONU.

\subsection{Objetivos de Desenvolvimento Sustentável da Agenda 2030 da ONU}

Chefes de Estado e de Governo e altos representantes, reunidos na sede das Nações Unidas em Nova York (EUA) em 25 a 27 de setembro de 2015, decidiram sobre os novos Objetivos de Desenvolvimento Sustentável (ODS) globais e, adotaram uma decisão histórica sobre um conjunto de Objetivos e 
metas universais e transformadoras que é abrangente, de longo alcance e centrado nas pessoas. A ONU informa que estão comprometidos "a trabalhar incansavelmente para a plena implementação desta Agenda em 2030". (ONU, 2015, p.3).

Com esta Agenda, buscam de maneira ampla, criar condições para um crescimento sustentável, inclusivo e economicamente sustentado, prosperidade compartilhada e trabalho decente para todos, tendo em conta os diferentes níveis de desenvolvimento e capacidades nacionais. O maior objetivo da ONU ao embarcar nesta grande missão de forma coletiva, conscientizando a todos que ninguém poderá ser deixado para trás, pois reconhecem a dignidade da pessoa humana como fundamental e querem que os objetivos e metas sejam cumpridos para todas as nações e povos.

A Agenda 2030 possui 17 ODS com 169 metas universais que envolvem todo o mundo, igualmente os países desenvolvidos e os em desenvolvimento. Eles são integrados e indivisíveis, e equilibram as três dimensões do desenvolvimento sustentável. Esses objetivos e metas estipuladas pela ONU são o resultado de mais de dois anos de consulta pública intensiva e envolvimento junto à sociedade civil e outras partes interessadas em todo 0 mundo, "prestando uma atenção especial às vozes dos mais pobres e mais vulneráveis". (ONU, 2015, p. 4).

Estes objetivos buscam concretizar os direitos humanos de todos e alcançar a igualdade de gênero e o empoderamento das mulheres e meninas. De acordo com as Nações Unidas, estes objetivos e metas estimularão a ação para os próximos 15 anos em áreas de importância crucial para a humanidade e para o planeta. (ONU, 2015).

Reconhecendo a importância dos profissionais bibliotecários e dos movimentos associativos ligados a IFLA, a instituição declara que, com o auxílio destes profissionais em todo o mundo, que contribuem com seu tempo, experiência e recursos financeiros, tornam possível a implementação dos ODS.

Por meio do planejamento estratégico das bibliotecas, e concomitantemente, com o fortalecimento da profissão por meio das entidades associativas, a FEBAB, no Brasil, assumiu este compromisso nacionalmente, 
promovendo ações, eventos e campanhas para intensificar os objetivos da IFLA, e por seguinte, comprometer a todos aos objetivos da Agenda 2030.

No contexto deste estudo, pode-se ser destacado, o objetivo 12 da Agenda 2030 - "Assegurar padrões de produção e de consumo sustentáveis", visando em suas metas: 12.2, alcançar a gestão sustentável e o uso eficiente dos recursos naturais; 12.3 , reduzir pela metade o desperdício de alimentos per capita mundial, nos níveis de varejo e do consumidor, e reduzir as perdas de alimentos ao longo das cadeias de produção e abastecimento, incluindo as perdas pós-colheita; 12.4, alcançar o manejo ambientalmente saudável dos produtos químicos e todos os resíduos, ao longo de todo o ciclo de vida destes, de acordo com o marco internacional acordados, e reduzir significativamente liberação destes para o ar, água e solo, para minimizar seus impactos negativos sobre a saúde humana e o meio ambiente; 12.5 , diminuir substancialmente a geração de resíduos por meio da prevenção, redução, reciclagem e reuso; 12.6, incentivar as empresas, especialmente as empresas grandes e transnacionais, a adotar práticas sustentáveis e a integrar informações de sustentabilidade em seu ciclo de relatórios; 12.7, promover práticas de compras públicas sustentáveis, de acordo com as políticas e prioridades nacionais; e 12.8, garantir que as pessoas, em todos os lugares, tenham informação relevante e conscientização para o desenvolvimento sustentável e estilos de vida em harmonia com a natureza. (ONU, 2019).

Com isso, evidencia-se a relevância de introduzir o Marketing Verde nas Bibliotecas, especificamente, ao garantir o acesso a informação relevante e promover a conscientização do desenvolvimento sustentável, sua importância e real implementação na gestão destas instituições, com apoio a IFLA e FEBAB.

\subsection{BiblioteCAS SUSTENTÁVEIS}

A disseminação da informação é subsídio relevante e decisório para posicionamentos importantes em contextos individuais e coletivos. Bibliotecas que promovam o acesso cumprem essa missão estão em consonância com as necessidades reais de seus usuários com o acesso livre, consciente, transparente e verdadeiro da informação. 
Cardoso e Machado (2017, p. 142), pontuam que a "biblioteca é um espaço de acesso, produção de informação e conhecimento e, o bibliotecário, um dos profissionais responsáveis pela disseminação da informação", assim acreditam que a introdução da temática da sustentabilidade na Biblioteconomia e na Ciência da Informação, torna-se determinante como agentes atuantes do acesso a informação, "além de se transformarem em protagonistas nesse cenário". As autoras expõem que, no âmbito internacional, o envolvimento das bibliotecas com as questões ligadas ao meio ambientes resultou em um novo conceito - o Green Library. (CARDOSO; MACHADO, 2017).

De acordo com o Dicionário Online de Biblioteconomia e Ciência da Informação (ODLIS), as Bibliotecas Verdes, são projetadas para minimizar o impacto negativo no ambiente natural e maximizar a qualidade ambiental interna por meio da seleção cuidadosa de locais, uso de materiais de construção naturais e produtos biodegradáveis, recursos (água, energia, papel) e eliminação responsável de resíduos, reciclagem e etc.).Concentram-se também em serviços, atividades, eventos, literatura e projetos relacionados, demonstrando 0 papel social e a responsabilidade das bibliotecas como líderes em sustentabilidade ambiental. (DICIONÁRIO ONLINE DE BIBLIOTECONOMIA E CIÊNCIA DA INFORMAÇÃO, 2019, tradução nossa).

Em 2002, a IFLA, preocupada e comprometida com a causa do desenvolvimento sustentável, lançou a declaração "Statementon Libraries and Sustainable Development" que aponta que o acesso à informação como fator preponderante e para a promoção do desenvolvimento sustentável. A IFLA declara que todos os seres humanos têm o direito fundamental a um ambiente adequado à sua saúde e bem-estar e essa declaração destaca ainda que os serviços da biblioteca devem promover o desenvolvimento sustentável e assegurar a liberdade de acesso à informação e ao conhecimento (IFLA, 2019, tradução nossa).

A IFLA informa que para receber o título de Biblioteca Verde, as instituições necessitam: criar consciência da responsabilidade social e liderança das bibliotecas em educação ambiental; apoiar o movimento mundial da Biblioteca Verde, preocupado com edifícios ambientalmente sustentáveis, 
recursos de informação ambientalmente sustentáveis e programação e conservação de recursos e energia; promover o desenvolvimento de iniciativas sustentáveis em nível local e mundial; e incentivar e apresentar ativamente suas atividades a uma audiência internacional.

Estas diretrizes são apresentadas pelo prêmio promovido pela instituição "IFLA Green Library Award"1, no qual visa escolher a melhor submissão da Green Library que comunica o compromisso da biblioteca com a sustentabilidade ambiental. A IFLA expõe que ao seguir a "Declaração da IFLA sobre Bibliotecas e Desenvolvimento Sustentável", o prêmio ajudará no avanço da profissão, por meio do esclarecimento do papel das bibliotecas e bibliotecários no avanço dos padrões de sustentabilidade e na promoção do conhecimento especializado dentro da prática profissional. (IFLA, 2019)

Reforçando estas diretrizes, Cardoso e Machado (2017), entendem que para uma biblioteca pública se transformar em biblioteca verde é preciso:

[...] estabelecer um Comitê Verde envolvendo funcionários da biblioteca e comunidade; e elaborar um plano de ação com os objetivos, metas, metodologia para implantação das ações e mudanças previstas ao longo de um determinado tempo. (CARDOSO; MACHADO, 2017, p. 142).

Contudo, verifica-se o quão relevante torna-se estabelecer comissões que tratam dos projetos sustentáveis e o engajamento dos profissionais da Unidade Informação, especialmente as Bibliotecas, a causa do desenvolvimento sustentável. Acredita-se na necessidade de criação de uma equipe comprometida com a temática e preocupada em concretizar o planejamento estratégico sustentável em sua instituição.

\section{PROPOSTA DE IMPLEMENTAÇÃO DO MARKETING VERDE NAS BIBLIOTECAS}

Buscando propor a implementação do Marketing Verde nas Bibliotecas, o presente estudo apresenta algumas diretrizes de atitudes sustentáveis em instituições, conforme Kotler (2012); Lam (2012); Moreno (2012); Eckschmidt e

\footnotetext{
${ }^{1}$ Qualquer tipo de biblioteca com um projeto, iniciativa ou ideia da Biblioteca Verde pode solicitar o Prêmio da Biblioteca Verde da IFLA. Fonte: https://www.ifla.org/node/10159
} 
Beskow (2014); e Cardoso e Machado (2017).

Primeiramente, estabelecer e compor uma comissão de assuntos sustentáveis dentro da biblioteca, a fim de criarem, proporem e monitorarem as ações sustentáveis dentro da instituição. Uma comissão com conhecimento técnico e teórico que possam participar de uma comunicação ou campanha de Marketing Verde, clara, honesta e transparente.

A seguir a Figura 01, apresenta um modelo adaptado pelos pesquisadores deste artigo a partir da proposta de Eckschmidt e Beskow (2014), para o funcionamento da comissão de assuntos sustentáveis em Bibliotecas, no qual sugere a formação da equipe de criação e implementação de ações sustentáveis em Bibliotecas, sendo que a mesma monitora e avalia os resultados ao oferecer o Marketing Verde, resultando na sensibilização e conscientização de usuários e a comunidade interna e externa mais conscientes.

Figura 01 - Modelo do funcionamento da comissão de assuntos sustentáveis em Bibliotecas

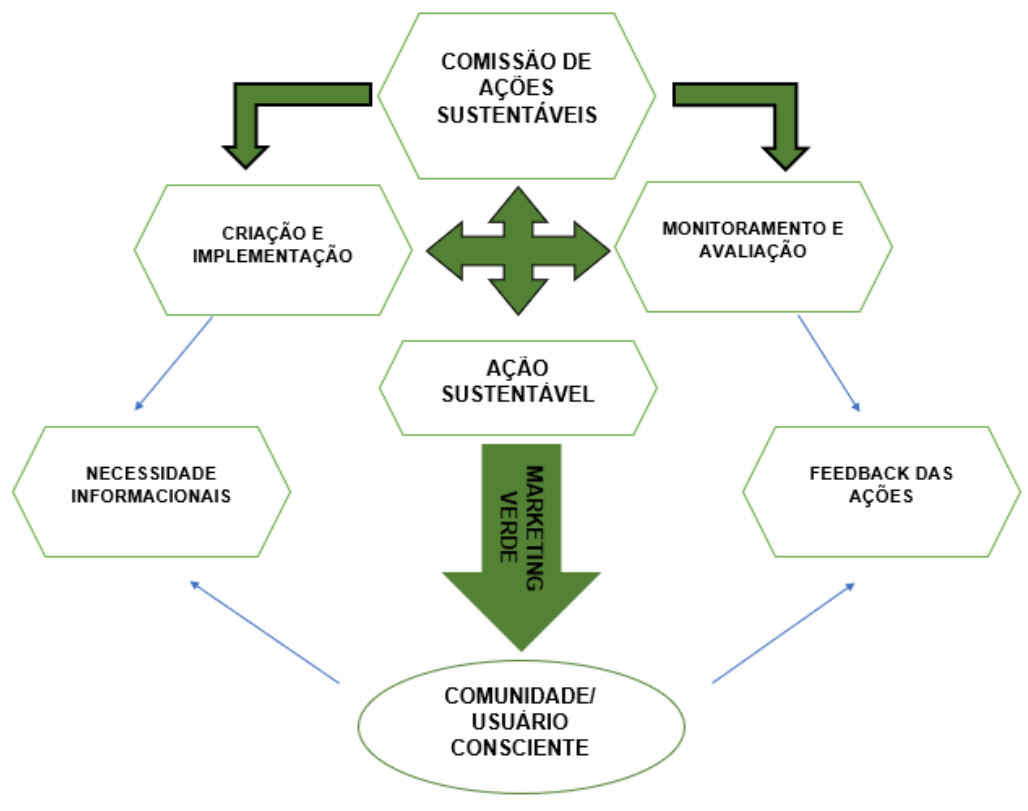

Fonte: Adaptado do modelo de Eckschmidt e Beskow (2014).

A comissão de ações sustentáveis em Bibliotecas ao pensar em estratégias de Marketing Verde, adaptadas as diretrizes apresentadas por Ottman (2012) em seu estudo sobre novas regras do Marketing Verde, deve-se se pensar em: 
a) Compreender e conhecer os Objetivos de Desenvolvimento Sustentável, em âmbitos ambientais, econômicos, sociais e os valores de seus usuários para desenvolver um plano de longo prazo para se alinhar com eles;

b) Criar produtos e serviços que equilibrem as necessidades dos usuários por qualidade, conveniência e capacidade de reduzir os impactos ambientais e sociais adversos aos serviços prestados na Biblioteca;

c) Desenvolver parcerias com marcas e fornecedores que ofereçam benefícios práticos enquanto fortalece e incentiva os usuários a respeito dos assuntos importantes que afetam a sua vida;

d) Promover a conscientização dos usuários quanto o uso de produtos e práticas sustentáveis, tal como descartes responsáveis e reciclagem correta; e

e) Comprometer de modo proativo, a fazer a sua parte para resolver problemas ambientais e sociais que surjam em sua comunidade.

Entretanto, ao pensar em novas regras do Marketing Verde, as Bibliotecas, tem que seguir alguns procedimentos estratégicos no seu planejamento sustentável. Obviamente, que além de desenvolverem atitudes comuns tal como: comprar papel reciclado, após o uso ao invés de descartá-los, pode-se reciclá-los; reciclar a tecnologia ultrapassada, utilizar e disponibilizar lixeiras de educação reciclável; promover uso consciente de copos sustentáveis; entre outros, a Biblioteca pode promover estratégias de ações de Marketing Verde.

Apresenta-se alguns procedimentos que podem ser estabelecidos e implementados em suas ações sustentáveis para realização do Marketing Verde, que vão de encontro com a Agenda 2030 e os Objetivos de Desenvolvimento Sustentável da ONU. Adaptado as sugestões apresentadas por Kotler (2012); Lam (2012); Moreno (2012); Eckschmidt e Beskow (2014); e Cardoso e Machado (2017): 
f) Analisar o ambiente de Marketing Verde: o primeiro passo é avaliar quais são os fatores externos e internos que podem influenciar a Unidade de Informação. Necessita-se deste modo analisar todo planejamento das ações sustentáveis, pontuando suas forças, fraquezas, público alvo e resultados esperados. Além disso, estabelecer o capital disponível que poderá ser usado nas ações de marketing, pois caso contrário, o plano não terá sustentabilidade a longo prazo.

g) Entender quem são os seus usuários: às vezes, o público alvo de sua biblioteca não é o usuário real, mas muitas vezes o potencial. O público alvo de uma determinada situação social em muitos momentos não atinge diretamente o usuário habitual da biblioteca, mas sim, o público externo. Com isso, a Biblioteca necessita elaborar um plano de marketing que seja voltado para o público alvo. Analisar os anseios de sua comunidade também é importante, prestando atenção nas demandas, na previsão de taxa de crescimento e de participação sociocultural e ambiental de todos.

h) Analisar e conhecer outras ações desenvolvidas em outras instituições: avalie e conheça as ações sustentáveis desenvolvidas em outras instituições. Estabelecer parcerias e troca de experiências com outros gestores e comissões de outras Unidades de Informação. Torna-se relevante conhecer o que vem sendo desenvolvido e que resulte em ações positivas e concretas, entretanto, deve-se levar em consideração a realidade da instituição, seu público alvo e objetivos.

i) Definir suas estratégias e ações sustentáveis: primeiramente, é necessário estabelecer o objetivo central e específicos do plano de ação. Após deve-se definir as estratégias para alcançá-los, mapeando todos os 
procedimentos. Um bom exemplo é utilizar a técnica dos $5 \mathrm{~W}_{2} \mathrm{H}^{2}$ : What? (o que), Who? (quem), When? (quando), Where? (onde), Why? (por que), How? (como), HowMuch? (quanto). Podendo incluir um novo "H" - HowMany? (quantos), ou seja, criando uma variação da técnica $(5 \mathrm{~W} 3 \mathrm{H})$, no intuito de estabelecer quantas pessoas que o plano de ação deseja alcançar (PLANEJAWEB, 2019).

j) Estabelecer parcerias e implementar as ações estabelecidas pelos órgãos, instituições, movimento associativos e fundações especializados: nacionalmente, um bom exemplo, é a Biblioteca estabelecer parcerias com a FEBAB, participando das ações em que a instituição vem realizando, juntamente com a IFLA, em relação aos Objetivos de Desenvolvimento Sustentável e a Agenda 2030.

k) Estabelecer um cronograma das ações: $O$ acompanhamento da duração de cada ação, os resultados e os recursos necessários que foram utilizados devem ser colocados no papel.

I) Monitorar e avaliar a ações sustentáveis promovidas na instituição: o monitoramento e avaliação de todas ações desenvolvidas devem ser realizadas pela gestão e/ou comissão de ações sustentáveis, avaliando os resultados, fraquezas e pontos fortes adquiridos, e assim, restabelecendo novos planos e ações.

m) Registrar e promover os resultados alcançados: torna-se relevante registrar todos os procedimentos realizados, recuperando dados positivos e negativos, e consequentemente, disseminar estes resultados para toda comunidade interna e externa da Unidade de Informação.

Acredita-se com a proposta de implementação de Marketing Verde as

\footnotetext{
${ }^{2} \mathrm{~A}$ planilha $5 \mathrm{~W} 2 \mathrm{H}$ é uma ferramenta administrativa que pode ser utilizada em qualquer empresa a fim de registrar de maneira organizada e planejada como serão efetuadas as ações. Fonte: https://sites.google.com/site/planejaweb/5w2h
} 
bibliotecas estarão em consonância com o que preconiza a IFLA e FEBAB na responsabilidade na inserção dos Objetivos do Desenvolvimento Sustentável da Agenda 2030 das Organizações Unidas (ONU).

\section{CONSIDERAÇÕES FINAIS}

O presente artigo objetivou propor a implementação de Marketing Verde em Bibliotecas e foi atendido em sua totalidade. Salientando que cada vez mais as questões ambientais veem se tornando uma constante e a exigência por parte da sociedade deve estar na pauta de discussão do governo e organizações em geral para buscar a redução dos impactos ao meio ambiente.

O Marketing Verde atualmente, pode ser visto como uma ferramenta necessária no planejamento estratégico da biblioteca, como um mecanismo relevante para a imagem positiva da instituição e a preocupação com o bemestar dos atores internos e externos em que esta se insere.

Nesta perspectiva, a Biblioteca, é a Instituição responsável pelo acesso a informação, e com isso, objetiva auxiliar seus usuários compreender a importância do desenvolvimento sustentável no contexto atual e para as gerações futuras.

A criação de uma comissão de ações sustentáveis torna-se ponto chave para o sucesso do plano de Marketing Verde na Unidade de Informação e, por conseguinte, estabelecer parcerias e conhecer ações e atitudes que outras instituições veem desenvolvendo em prol do desenvolvimento sustentável, também podem ser uma boa iniciativa.

A IFLA, e nacionalmente a FEBAB, vem incansavelmente estabelecendo projetos e ações para realização dos Objetivos de Desenvolvimento Sustentável da Agenda 2030 promovida pela ONU. Com isso, as Bibliotecas podem introduzir estes objetivos em seus planos de ações sustentáveis, podendo assim, obterem sucesso no Marketing Verde.

Diferenciar as ações reais de Marketing Verde de ações vistas como Greenwashing, são importantes para imagem da instituição. Por isso, torna-se viável conhecer regras, procedimentos e técnicas de marketing e, obviamente, aprofundar os estudos teóricos sobre sustentabilidade e desenvolvimento 
sustentável.

Neste estudo, apresentou-se propostas para conhecer os princípios, conceitos e alcançar os objetivos do desenvolvimento sustentável, e a relevância do uso do Marketing Verde em Bibliotecas. A pesquisa demonstra procedimentos que podem ser estabelecidos e implementados em ações sustentáveis para realização do Marketing Verde, que vão ao encontro com a Agenda 2030 e os Objetivos de Desenvolvimento Sustentável da ONU.

Contudo, pontua-se a relevância de promover ações com a comunidade da biblioteca, visto que o desenvolvimento sustentável é um modo de compreender o mundo como uma interação do homem e o meio ambiente, buscando prever e conscientizar as atitudes das pessoas nas diferentes dimensões (econômica, ambiental, institucional e social).

O acesso a informação é um elemento chave para conscientização da necessidade, importância e implementação de ações sustentáveis em todo contexto da vida humana associada.

\section{REFERÊNCIAS}

CARDOSO, Nathalice Bezerra; MACHADO, Elisa Campos. Bibliotecas verdes e sustentáveis no Brasil. Transinformação, Campinas, v. 29, n. 2, p.141-149, maio 2017. Disponível em: http://www.scielo.br/scielo.php?pid=S0103-

37862017000200141\&script=sci_abstract\&tlng=pt. Acesso em: 02 jul. 2019.

CASTRO, Bruno Roberto Viana et al. O marketing verde na tecnologia da informação: percepções das atitudes e comportamentos dos profissionais de TI e ações para incrementar o marketing verde nesse setor. Revista de Gestão Ambiental e

Sustentabilidade, São Paulo, v. 5, n. 1, p.2-17, abr. 2016. Disponível em: http://www.revistageas.org.br/ojs/index.php/geas/article/view/170. Acesso em: 30 jun. 2019.

ECYCLE. Greenwashing: entenda o que é e evite. 2019. Disponível em: https://www.ecycle.com.br/component/content/article/6-atitude/2094-definicao-o-quecomo-traducao-greenwashing-estrategias-marketing-propaganda-consumo-produtosservicos-atitude-apelo-ambiental-enganosa-empresas-consciencia-ambiental-casosexemplos-cuidados.html. Acesso em: 30 jun. 2019.

ECKSCHMIDT, Alex; BESKOW, Eduardo. Sustentabilidade: para todos - faça sua parte! Florianópolis: Insular, 2014. 181 p.

IFLA. IFLA Green Library Award. 2019. Disponível em: https://www.ifla.org/node/10159. Acesso em: 26 jun. 2019. 
KOTLER, Philip. Marketing para o século XXI. 12. ed. São Paulo: Futura, 2002.

LAM, Camila. 5 passos para elaborar um bom plano de marketing. 2012.

Disponível em: https://exame.abril.com.br/pme/5-passos-para-elaborar-um-bom-planode-marketing/. Acesso em: 30 jun. 2019.

MOREIRA, Cleber Vasconcelos. Marketing verde como propensa vantagem competitiva sustentável de uma organização. Foco, Espirito Santo, v. 8, n. 2, p.133144, ago. 2015. Disponível em:

http://revistafocoadm.org/index.php/foco/article/view/183. Acesso em: 29 jun. 2019.

MORENO, Nelcy Rocío Escobar. Las comunicaciones integradas de marketing (CIM) como pilar de la estrategia de marketing verde y sus implicaciones en La gestión ambiental. Revista Faculdade de Ciências Econômicas, Colômbia, Bogotá, v. 20, n. 2, p.69-79, jan. 2012. Disponível em: http://www.scielo.org.co/pdf/rfce/v20n2/v20n2a05.pdf. Acesso em: 30 jun. 2019.

MISHRA, Pavan; SHARMA, Payal. Green Marketing: Challenges and Opportunities for Business. Management Edge, Pune, v. 7, n. 1, p.78-86, jan. 2014. Disponível em: https://www.researchgate.net/publication/302589120_Green_Marketing_Challenges_and_Opportunities. Acesso em: 30 maio 2019.

PLANEJANDOWEB. O que é 5W2H. 2019. Disponível em: https://sites.google.com/site/planejaweb/5w2h. Acesso em: 26 jun. 2019.

ODLIS. Online Dictionary for Library and Information Science. 2019. Disponível em: https://www.abc-clio.com/ODLIS/odlis_A.aspx. Acesso em: 26 jun. 2019.

ONU. Transformando Nosso Mundo: A Agenda 2030 para o Desenvolvimento Sustentável. 2015. Disponível em: http://www.br.undp.org/content/dam/brazil/docs/agenda2030/undp-br-Agenda2030completo-pt-br-2016.pdf. Acesso em: 20 jun. 2019.

ONUBR. Nações Unidas do brasil. 2019. Disponível em: https://nacoesunidas.org/. Acesso em: 19 jun. 2019.

OTTMAN, Jacqueliyn A. Marketing Verde: desafios e Oportunidades para a nova era do Marketing. 1르 ed. São Paulo: Makron Books Ltda, Pág. 18-44, 1994.

OTTMAN, Jacqueliyn A. Marketing Verde: desafios e Oportunidades para a nova era do Marketing. 1ª ed. São Paulo: Makron Books Ltda, Pág. 18-44, 1994.

SACHS, Jeffrey D. The age of sustainable development Columbia University Press: New York, 2015. 565 p.

TAVARES, Fred; FERREIRA, Giselle Gama Torres. Marketing verde: um olhar sobre as tensões entre greenwashing e ecopropaganda na construção do apelo ecológico na comunicação publicitária. Revista Espaço Acadêmico, Maringá, v. 7, n. 138, p.23-31, nov. 2012. Disponível em:

http://periodicos.uem.br/ojs/index.php/EspacoAcademico/article/view/18725. Acesso em: 30 jun. 2019. 


\title{
GREEN MARKETING: PROPOSAL FOR SUSTAINABLE LIBRARY ATTITUDES
}

\begin{abstract}
Introduction: Green Marketing is a relevant tool to be part of the strategic planning of large, media and small organizations, as well as unused and administrative bodies. Presenting itself as an important mechanism to establish a positive image and demonstrate the concern of non-profit and non-profit organizations with the quality of life on the planet and society in general. This study indicates the perspective that Green Marketing may be suitable for Libraries, such as those responsible for the access, use and dissemination of information in their user community, the reform of sustainable development actions in the current context and for the next ones presentations. Objective: This way or objective of this article is to propose the implementation of Green Marketing in Libraries. Even so, that this theme needs broad reflection and insertion, since sustainability is one of the most discussed and idealized concepts today. Methodology: It is characterized as applied and exploratory research as technical procedures for bibliographic and documentary research, with the proposal of implementing Green Marketing for Libraries based on the model adapted from the proposal by Eckschmidt and Beskow (2014). Results: proposals are presented to know the principles, concepts and achieve the objectives of sustainable development, and the relevance of the use of Green Marketing in Libraries, demonstrating procedures that can be implemented in sustainable actions for the realization of Green Marketing, which meet the 2030 Agenda and the UN Sustainable Development Goals.
\end{abstract}

Descriptors: Green Marketing. Greenwashing Green marketing. Libraries Sustainable Information.

\section{MARKETING VERDE: PROPUESTA DE ACTITUDES DE BIBLIOTECA SOSTENIBLES}

\begin{abstract}
RESUMEN
Introducción: Green Marketing es una herramienta relevante para formar parte de la planificación estratégica de organizaciones grandes, mediáticas y pequeñas, así como de organismos administrativos y no utilizados. Presentarse como un mecanismo importante para establecer una imagen positiva y demostrar la preocupación de las organizaciones sin fines de lucro y sin fines de lucro con la calidad de vida en el planeta y la sociedad en general. Este estudio indica la perspectiva de que Green Marketing puede ser adecuado para las bibliotecas, como los responsables del acceso, uso y difusión de información en su comunidad de usuarios, la reforma de las acciones de desarrollo sostenible en el contexto actual y para las próximas presentaciones. Objetivo: esta forma u objetivo de este artículo es proponer la implementación de Green Marketing en Bibliotecas. Aun así, este tema necesita una amplia reflexión e inserción, ya que la sostenibilidad es uno de los conceptos más discutidos e idealizados en la actualidad. Metodología: Se caracteriza como investigación aplicada y exploratoria como procedimientos técnicos para la investigación bibliográfica y documental, con la
\end{abstract}


propuesta de implementar Green Marketing para Bibliotecas basada en el modelo adaptado de la propuesta de Eckschmidt y Beskow (2014). Resultados: se presentan propuestas para conocer los principios, conceptos y alcanzar los objetivos del desarrollo sostenible, y la relevancia del uso del Green Marketing en las Bibliotecas, demostrando procedimientos que pueden implementarse en acciones sostenibles para la realización del Green Marketing, que cumplan con Agenda 2030 y los Objetivos de Desarrollo Sostenible de la ONU.

Descriptores: Marketing Verde. Lavado verde Comercialización verde. Bibliotecas Información sostenible

Recebido em: 25/11/2019

Aceito em: 21/04/2020 